\title{
OS AGENTES DA CONSTRUÇÃO POLÍTICA DO MERCADO
}

\author{
José Ferreira $^{1}$
}

\section{Introdução}

O mercado é vulgarmente definido como local de encontro entre consumidores e produtores. No entanto, o mercado é também ele produzido. Produzido por pessoas que não são necessariamente os consumidores e os produtores que se encontram nesse mercado. Ou, pelo menos, não são apenas isso. Aquilo que os define é, antes de mais, a sua atividade militante na construção desse mercado. É com esta perspectiva que eu procuro compreender a criação e gestão do Circuito Carioca de Feiras Orgânicas. O circuito foi oficialmente criado a 25 de janeiro de 2012, com a publicação do Decreto n. 35.064 pela Prefeitura do Rio de Janeiro. Mas já funciona desde 2010. Atualmente é composto por dez feiras geridas por três organizações diferentes. À exceção de duas, todas se situação na Zona Sul, isto é, nos bairros nobres da cidade do Rio de Janeiro. Participam nelas, como vendedores, agricultores associados em núcleos de comercialização ou não, provenientes em sua maioria dos municípios da Região Serrana do Estado. Os consumidores são, obviamente, moradores do bairro.

No entanto vale insistir: o objeto de pesquisa não é o circuito, mas sim o trabalho político que o fez surgir e o faz existir. É necessário ter bem claro este ponto por duas razões. Primeiro, a cultura política daqueles que constroem no mercado tendem a ver os seus usuários, os produtores de agricultura orgânica, como "protagonistas" do circuito. No entanto, aceitar este "protagonismo" é proceder a uma mudança de objeto. Não seria mais do estudo etnográfico da produção do mercado mas a etnografia do mercado em si.

Então: o objeto aqui não seria o Comitê Gestor do Circuito - uma conselho, sob coordenação da Secretaria Especial de Desenvolvimento e Economia Solidária da Prefeitura do Rio de Janeiro, onde participam representantes dos produtores, associações de moradores e organismos da Prefeitura com o fim de gerir o circuito? Não. O comitê gestor e as feiras são dois produtos de mesmo trabalho político de um conjunto de pessoas empenhadas em dinamizar o mercado de orgânicos no Estado do Rio de Janeiro. O objeto desta pesquisa é esse trabalho. Portanto, (eis a segunda razão

\footnotetext{
${ }^{1}$ Universidade Federal do Rio de Janeiro, Brasil.
} 
para insistir na delimitação do objeto) as fronteiras deste objeto de estudo são mais fluidas do que aparentam quando afirmo: "eu estudo o Circuito Carioca de Feiras Orgânicas",2.

\section{Os agentes da construção do mercado}

As estória de vida que são apresentadas aqui foram escolhidas de um modo simples. Eu havia começado a pesquisa me dirigindo às feiras do Circuito Carioca e tentando estabelecer o diálogo com os produtores. Não obstante, esta abordagem é incompatível com a minha personalidade e, sei hoje, com o ritmo de trabalho na feira. Algumas vezes consegui me apresentar a um ou outro produtor. Mas ele logo passava a dar mais atenção a um verdadeiro cliente. Outras vezes fiquei a um canto observando e lendo.

Então decidi abordar as feiras de outro modo. Contatei Fábio Ramos, o ex-sócio de um amigo meu. Sua empresa fez algumas consultorias para a Associação de Produtores Biológicos do Rio de Janeiro (ABIO) que coordena seis das nove feiras. Chiquinho Abelha, colaborador da consultora, me escreveu um e-mail: "Acho interessante você contatar com a Cristina Ribeiro da ABIO, que foi a pessoa que lutou para conseguir a liberação das feiras livres orgânicas do Rio". Assim, decidi entrevistar Cristina. E nessa entrevista, Cristina insistiu com igual veemência que eu entrevistasse Paulo Aguinaga.

Me decidi pela técnica de entrevista com um duplo intuito: recolher a história do processo que estou pesquisando; e estabelecer as relação que não consegui estabelecer nas visitas às feiras. No entanto, a seleção dos interlocutores foi mais do que um acaso de pesquisa. A insistência com que Cristina me recomendou entrevistar o Paulo Aguinaga foi muito semelhante àquela que o Chiquinho Abelha havia usado para me convencer a entrevistar ela. Esta semelhança obrigou à minha reflexão. Creio existir aqui uma analogia entre a vida social e o processo de pesquisa: como agentes sociais e como etnógrafos necessitamos de contar com as pessoas "certas". E me recomendaram

\footnotetext{
${ }^{2}$ A importância deste fato se torna visível quando se "descobre" que as feiras reorganizaram outros canais de comercialização da produção orgânica, em especial a venda através de lojas e a venda a restaurantes. Antes, o produtor "descia" (isto é, viajava de um dos municípios da Região Serrana do Estado do Rio de Janeiro, onde se concentra a produção orgânica, à cidade capital do Estado) para levar a sua produção a cada um dos seu clientes. Hoje, o produtor "desce" para feiras e são os donos de lojas e restaurantes que se deslocam às feiras para buscar as suas encomendas já previamente separadas pelo produtor. De certo modo, o Circuito Carioca de Feiras Orgânicas adquiriu traços de - pala usar as palavras de uma interlocutora - um mercado abastecedor de produtos orgânicos.
} 
as pessoas que, para eles meus interlocutores, eram certas. Isso diz algo da realidade social. Ao mesmo tempo, um tal encaminhamento da pesquisa ficaria obviamente assente sobre a categoria teórica capital simbólico. Um acaso de pesquisa apareceu assim articulando empiria, metodologia e teoria. Se exige então trilhar este caminho até às últimas consequências.

\subsection{Cristina Ribeiro}

Encontrei Cristina a um sábado, na feira orgânica do Jardim Botânico. Havíamos marcado o encontro por e-mail. Eu expliquei as minhas pretensões com a pesquisa e ela me resumiu a história do circuito. Então marcamos para a quinta-feira seguinte uma entrevista com gravador. Realizámos a entrevista em sua casa. Mais tarde, com o intuito de preparar este artigo, realizamos uma segunda entrevista de forma a recolher alguns dado da sua história pessoal em torno da agricultura orgânica. Essa história será contada pelas suas palavras.

Eu terminei a faculdade e fui fazer mestrado lá no Museu Nacional. E depois fui para o campo, para roça, ser agricultora. Eu abandonei mesmo a vida acadêmica [sem completar o mestrado]. Eu descobri que não era para mim. E eu me lembro que falei para você que, na verdade, o que me levou para o campo foi a questão da alimentação. Primeiro, eu quero ter um trabalho que eu possa trabalhar do lado dos meus filhos. Não quero deixar filho em creche, sair para trabalhar e voltar para casa. E segundo eu quero plantar a minha comida, ou pelo menos uma boa parte dela. Porque essa comida aí não me está fazendo [bem] à cabeça.

Aí eu fui ser agricultora e fundámos a associação. Isso foi em 1985. Um grupo de dezoito. A gente diz que eram os 18 do Forte. (...) Todos neo-rurais. Na verdade, essas pessoas foram-se conhecendo e resolveram fazer uma feira de produtos orgânicos lá em [Nova] Friburgo. E a feira nasceu antes da ABIO, da associação. Então a gente se juntou para fazer a feira. E implantamos a feira. Acho que foi a primeira do Brasil (Cristina Ribeiro, entrevista, 16/05/2013).

Cristina Ribeiro se confunde com a ABIO. Quando lhe pergunto há quanto tempo trabalha com a ABIO, a resposta imediata é: "Menino! Desde que me conheço por gente". Fundadora da associação, como ela conta, foi igualmente Presidente entre 2005 e 2009 e Diretora Executiva entre 2002 e 2005 e, novamente, desde 2009 à atualidade. Apesar da ABIO ter nascido da organização de uma das primeiras feiras de produtos orgânicos do Brasil, durante a década de 1990, a associação esteve dedicada à construção de um sistema de certificação da produção orgânica. Esse período da história das associações foi objeto de estudo de dissertação de uma das suas associadas, Fernanda Fonseca (1999). 
Por outro lado, quando Cristina explica o empenho da associação em promover a comercialização dos produtos orgânicos, empenho posterior a 2007, enquadra sempre essa decisão no "terramoto dos supermercados". Ela referiu isso logo no nosso primeiro encontro e, portanto, a primeira entrevista que tivemos debruçou-se bastante sobre esses dois períodos do mercado orgânico no Rio de Janeiro: a época dos supermercado, a época das feiras.

1992 foi um marco para os produtos orgânicos. [A Conferência das Nações Unidas sobre o Meio Ambiente e o Desenvolvimento, ECO-92, realizada no Rio de Janeiro] foi um marco para os produtos orgânicos porque chamou a atenção da população para o alimento, e para a relação entre o alimento e o meio ambiente. E foi nítido como os consumidores mudaram a percepção. A televisão, os jornais, todo o mundo falando de agrotóxico... Assim aumentou a demanda. A gente vivia, primeiro, da feira em Friburgo, onde nasceu a ABIO. Depois em feirinhas em clubes, igrejas, condomínios, sempre num cantinho comercializando as coisas. Aí surgiu a feira da Glória, ainda na onda da ECO-92. A produção começou a crescer também com essa demanda. Mas os canais para chegar até ao consumo não existiam.

A gente... Na verdade eu. Eu falava muito na ABIO: a gente precisa de entrar em supermercado. O pessoal de São Paulo já estava em supermercado. Mas não tinha muito eco. Até que um dia na feira da Glória, o professor René Carvalho, da economia da UFRJ, estava lá fazendo uns estudos sobre orgânicos. E aí, conversando, comentei com ele: "Está difícil comercializar. A gente não consegue escoar a produção; não consegue sobreviver. Vamos ficando só os neo-rurais que têm outra fonte de renda". Aí o professor René falou: "Olha só, se você pensa em entrar em supermercado, tem um supermercado que é a cara do orgânico. O Zona Sul. Um supermercado diferenciado, são lojas menores, produtos caros, produtos importados...". A gente vê um Zona Sul e passa em frente. "Ele é a cara dos orgânicos".

A ABIO, enquanto ABIO, não quis se envolver. Eu e outra produtora lá de Friburgo, a Jovelina, fomos lá bater à porta. Identificámos o comprador. Falámos em nome da ABIO. Duas malucas chegando lá... Levámos a instituição junto. Ele se interessou mas não muito. Eu sei que ele depois fez uma viagem à Europa e viajou já com a luzinha acesa. Orgânico por todo lado: em supermercados, lojas de orgânicos. Ele voltou entusiasmado e ligou para a gente. Era na minha casa, lá em Friburgo, que a gente juntava a produção, empacotava, etiquetava - porque tinha que ser assim, né? -, botávamos tudo no carro da Jovelina, que era um carro comum, e partíamos para Ipanema. Não me lembro mais quantas vezes por semana. Claro que isso era inviável para duas produtoras probretonas sem carro e sem gente para trabalhar. Aí eu falei: Jovelina, vou sair. Ela também decidiu não continuar e entregamos essa abertura no mercado Zona Sul para o Sítio do Moinho. Entregamos e eles seguiram (Cristina Ribeiro, entrevista, 7/03/2013).

Vários supermercados se interessaram pela produção orgânica. E várias empresas surgiram a produzir para eles. Com dimensões e estruturas diferentes. Duas empresas de maior dimensão foram criadas por investidores financeiros: o Sítio do Moinho e a Agrinatura. Por vezes, Cristina se referiu a ambos como "os banqueiros". Apareceu também a Horta Orgânica, uma cooperativa de agricultores familiares, da qual Paulo Aguinaga falará abaixo. E o Vale das Palmeiras, uma empresa do ator de novelas 
Marcos Palmeira, que conseguiu sobreviver mesmo quando, de repente, o comércio via supermercados começa a ser inviável.

Seis. Aí foi caindo um por um. Nem sei quem caiu primeiro. A Agrinatura faliu. E parece que até o banqueiro quebrou. A Horta Orgânica fechou as portas dramaticamente. Dramaticamente! O Vale das Palmeiras foi ficando... E aí a agricultura orgânica [Cristina sibila e indica, com a mão, uma descida íngreme] ladeira a baixo. O que provocou esse maremoto? Sei lá. É uma relação absolutamente massacrante. Eles te obrigam a ter uma série de condições: código de barras, embalagem do produto... E tem o que eles chama de enxoval. Você tem que ficar dando bônus, produto de graça. Para você manter o espaço ali. Porque os supermercados é como um shopping onde os espaços estão divididos entre as empresas que querem ali vender. É uma despesa muito grande e uma logística infernal. Você vai entregar meia dúzia de caixas em cada loja, uma em cada ponto da cidade. $\mathrm{O}$ veículo chega e você fica na fila para entregar. Uma hora na fila para entregar meia dúzia de caixas. E depois tem esse custo de conquista e manutenção do espaço no supermercado - o que eles chamam do enxoval. E é uma venda à consignação. Você recebe pelo que vendeu. E quem diz o que sobrou são eles; você não recebe de volta (idem).

A "aventura nos supermercados" não durou muito. Em 2001, Cristina fez a primeira entrega da sua produção no Zona Sul. Em 2007, a ABIO realiza um seminário para debater o problema da comercialização, “já a tragédia estava consumada".

Cara, eu deixei porque tive assim tantas decepções comerciais. Uma dificuldade de comercializar os produtos, uma loucura. Não dá para ficar, tendo que sair de vez em quando para fazer consultoria ou depender do dinheiro do marido para sobreviver. Os supermercados foram a minha penúltima tentativa. Acho que vou voltar para a academia. Pelo menos tem bolsa de estudo, é mais fácil. Aí vim fazer prova para o CPDA, mas estudei só um semestre. A tentação voltou de novo. Eu falei: vou dedicar-me à $\mathrm{ABIO}$ para a $\mathrm{ABIO}$ ser realmente um apoio para os agricultores (Cristina Ribeiro, entrevista, 16/05/2013).

Aí nós, a ABIO, fizemos um seminário de comercialização em 2006 ou 2007. Foram poucas pessoas, mas foram pessoas importantes. A gente saiu de lá convicto que o nosso caminho eram as feiras. E começou o trabalho de bater na porta da prefeitura para conseguir licença para outras feiras [para além da Glória, que existe desde 1994]. A gente falou com vários Secretários. Vai lá ou manda assessor; não resolve nada. Cheguei a tomar café da manhã com um deputado do DEM. A conversa terminou "Deixe estar, eu vou falar pessoalmente com o César" ${ }^{3}$. Nunca mais consegui falar com o sujeito!!! Sumiu. Evaporou.

Paralelamente, existe a Comissão da Produção Orgânica, coordenada pelo Ministério da Agricultura. Trabalhámos bastante. Fizemos uma primeira versão do Regulamento Interno das feiras. Mas [é] impressionante o desinteresse das organizações pela questão da comercialização. Eram reuniões em que, muitas das vezes, estava eu e uma amiga do SEBRAE. Assim! Nenhuma [outra] organização. E a gente começou, enfim, a procurar abrir essa brecha na Prefeitura em nome da Comissão da Produção Orgânica (idem, 7/03/2013).

Por recomendação de um amigo, Nelson (de quem Paulo Aguinaga falará brevemente abaixo), Cristina procurou Mário Del Rei, vereador pelo PCdoB no Rio de

3 Trata-se de César Maia, Prefeito do Rio de Janeiro entre 1993 e 1999 e entre 2001 e 2007.

Iluminuras, Porto Alegre, v. 14, n. 33, p. 87-99, jul./dez. 2013 
Janeiro e subsecretário na Secretaria Municipal de Cultura. Entretanto, o Prefeito era Eduardo Paes e não mais César Maia, referido acima.

Mario Del Rei, antigo PDT, daquela turma brizolista das antigas da qual eu fui... me aproximei durante algum tempo. Conhecia esse Mário Del Rei de eventos políticos partidários. E fomos lá, junto com o, na época, gerente da feira da Glória. Liguei para o Mário Del Rei e lá fomos os dois falar com ele. [Falando como se fosse Mário Del Rey:] "Não, vamos pensar uma forma de não-sei-o-quê, feiras culturais...". E bom, ficamos a tentar achar a forma de, pela cultura, conseguir o licenciamento de outras feiras para além da Glória. Porque feiras convencionais não pode surgir nenhuma. Tem uma lei que proíbe a implantação de feiras na cidade do Rio de Janeiro. Feiras convencionais; não feiras-evento.

Aí sei que, de repente, alguns dias depois ele me liga. "Olha só, a gente está querendo fazer algo. Está com um projeto da Claro (a [empresa de] telefonia) de reativação da vida diurna da Lapa. Vai ter show, comida, artesanato... Vamos botar uma feira orgânica?". Resumindo: acho que dos doze [eventos previstos] só aconteceram nove. Foi um fracasso. Não só a feira orgânica; também os shows. Pouquíssima gente. Um calor! Em pleno verão. Ali não tem uma árvore, nada. Muita gente [da política] veio visitar: deputados, a Jandira Fegali ${ }^{4}$... Bom, mas nada de concreto para implantar feiras.

Nesse meio tempo teve um evento da semana da alimentação no Leme. Da semana do alimento orgânico. Acontece sempre em maio. Uma feira organizada por esse exgerente da feira da Glória. E foi uma pessoa da equipe técnica da ABIO lá olhar. Ali conheceu Rosemary Gomes que, nessa época, trabalhava na Secretaria Especial de Desenvolvimento e Economia Solidária. Conversaram... Precisamos de novas feiras. E ficamos de conversar. Fomos lá várias pessoas da ABIO e ela se sensibilizou, porque era uma pessoa ligada à economia solidária. A SEDES é, no governo de Eduardo Paes, território do PT. O Secretário, na época Marcelo Costa do PT, chamou a Rosy Gomes porque ela é uma pessoa conhecida no movimento da economia solidária e comércio justo. E foi a nossa sorte; eles caíram de braço dado com a gente.

Então a Rosy ia com a gente. Nós fizemos reuniões, uma ou duas pelo menos, com cada associação de moradores. Primeiro tinha que ter o O.K. deles. "Beleza! Podem vir" - assim, super fácil com as associações de moradores. E chamamos a Secretaria Especial de Ordem Pública... Chamamos, não; a SEDES chamou. Porque é a SEOP que autoriza o uso do espaço público na cidade, quem licencia as feiras, mesmo as convencionais. (Eu acho isso inominável, que não tenha uma secretaria de abastecimento em algum lugar. A feira convencional é tratada como uma questão de ordem pública. Como camelô, que leva porrada de guarda...). Preparámos uma apresentação. Foi aí que eu levei a foto da feira de Paris que te contei. Feira em Paris, feira em Boston, feira em Londres... "Oooooh! Oooooh! Oooooh!" [Parodiando a atitude dos membros da SEOP]. Aquela feira bonitinha com tudo escrito em inglês, sabe? Cara, é impressionante. Foi isso que sensibilizou aquela SEOP. E aí eles deram a ideia de que saísse um Decreto do Prefeito criando o Circuito Carioca de Feiras Orgânicas.

E assim sabe quando acontece uma revolução? Você está numa situação e você vira e cabeça para baixo? Quatro feiras autorizadas no filé mignon da Zona Sul. A gente falou: queremos, no Leblon, a Rua Antero de Quental. Crente que eles iam empurrar a gente para uma praça bem escondida lá no fím do mundo. Beleza, liberado! Em Ipanema, a gente quer a Nossa Senhora da Paz. Aliás, a gente queria a General Osório, mas eles não: a General Osório já tem muita muvuca. Então a gente quer a Nossa Senhora da Paz. Perfeito! Em Copacabana a gente quer o Bairro Peixoto. A única que não foi onde a gente queria originalmente foi no Jardim Botânico. Eles queriam feira no Jardim Botânico mas não naquela praça. Esqueci o nome. E

\footnotetext{
${ }^{4}$ Deputada federal pelo PCdoB e, na época, Secretária de Cultura da Prefeitura.
} 
sugeriram para a gente a São José da Lagoa... que se mostrou muito melhor. Não circula pedestre, mas passam muito carro. E tem estacionamento fácil.

Em 2010, em maio de 2010, surgem as novas feiras. O Decreto do Prefeito só saiu em 2012. No meio tempo, a situação ainda só contava com a autorização da subprefeitura. Até ao início de 2012, o Circuito Carioca de Feira Orgânicas era a ABIO. Mas aí haviam outras feiras que funcionavam com uma autorização precária da Região Administrativa, que são uma racha da feira da Glória. E a SEDES resolveu abrigar também essas feiras no decreto. Essas feiras são coordenadas por outra organização, a Essência Vital. E agora está a ser criada outra em Jacarepaguá, que vai que coordenada por uma organização apoiada pela AS-PTA (Cristina Ribeiro, entrevista, 7/03/2013).

Como se nota, a história do Circuito Carioca de Feiras Orgânicas está decididamente ligada à história recente da $\mathrm{ABIO}$ e, por acréscimo, à história profissional da sua Diretora Executiva, Cristina Ribeiro. Esse fato pesou sem dúvida para o sucesso da entrevista. Nas entrevistas eu raramente fiz perguntas e, quase sempre, apenas para pedir esclarecimento sobre quem é um pessoa, uma organização ou o significado de uma sigla. Sem dúvida, não se pode ignorar a personalidade do interlocutor ao avaliar o sucesso da entrevista. Mas este sucesso se deve, em boa medida, à coincidência entre o meu objeto de pesquisa e a trajetória profissional recente de Cristina Ribeiro.

\subsection{Paulo Aguinaga}

A estória apresentada aqui deve ser tomada como provisória. Contatei o Paulo também por e-mail. E como ele não vive no Rio de Janeiro, me desloquei a Petrópolis, ao Horto Mercado de Itaipava, para realizar a entrevista. Com tal, não tive a oportunidade de antecipar a entrevista com uma conversa informal prévia que me ajudasse a preparar um guião. Portanto, espero complementar os dados aqui apresentados em um próximo encontro com Paulo.

Eu entrei em 77 na Universidade Rural [Universidade Federal Rural do Rio de Janeiro]. Insatisfeito com o curso, fui convidado a morar num sitio em Friburgo. João Carlos Ávila tinha chegado da Alemanha e estava trazendo a proposta da [agricultura] biodinâmica. Ele me convidou para a gente produzir no sítio dele. A gente produziu; a gente fez lá a primeira feirinha orgânica do Estado... De forma completamente maluca. E lá no João eu tive a oportunidade de entrar em contato não só com essa literatura da biodinâmica, mas também com essa parte do cooperativismo. O João era um cara muito estudioso; e a gente estudava muito.

Então uma pessoa escreveu para o Jornal do Brasil, que na época era um jornal de grande circulação. Essa pessoa era o Joaquim Moura. Escreveu uma carta para aquela seção das Cartas dos Leitores falando da preocupação $\mathrm{cm}$ a contaminação dos alimentos, etc. etc. e propondo, de forma bem genérica, a criação de uma cooperativa de consumidores e produtores. Aí, surpreendentemente, essa carta teve uma grande resposta. Um grupo de pessoas que não se conhecia respondeu a essa carta. E se marcou um encontro lá no Parque Lage para amadurecer essa ideia. A 
carta foi em 79 e o encontro foi também em 79. Eu já estava envolvido com a produção orgânica e com o ideal do cooperativismo e então falei: eu quero fazer isso. E me juntei ao grupo na fundação e formação da CONATURA.

$\mathrm{Na}$ verdade, CONATURA é um nome muito grande: Cooperativa de Produtores e Consumidores de Ideias, Produtos e Soluções Naturais. Uma coisa bem ousada e abrangente. E com objetivos muito amplos. Era militância ecológica, produção orgânica, distribuição dos produtos, etc. E durante muito tempo a CONATURA teve um braço de militância ecológica muito forte, com ações antinuclear, movimentos pela paz... Muito antes da parte comercial. Até porque na época não havia produção orgânica no Estado. Ou, se havia, era muito desarticulada, entendeu? Participei dessa militância ecológica, que na época estava muito forte. Depois decidi resolver então resolver essa questão [de falta de produção]. A gente tinha cooperativa mas não tinha produto.

A minha família sempre teve casa em Petrópolis; passávamos férias lá. Era um município de que eu gostava muito. Aí procurei e acabei por puro acaso caindo num sítio lá no Brejal. Isso foi no início de 1980. Eu, com a experiência que tinha adquirido lá no sítio do João, me mudei para Petrópolis, para o Brejal, e comecei a produzir... Para vender na CONATURA. Era só eu. Eu com dois cestos. Um negócio completamente amador. Totalmente ideológico! Andava sete quilómetros para pegar o ônibus do Brejal até à Posse. Depois da Posse para Petrópolis e de Petrópolis para o Rio.

Mas o negócio foi crescendo... porque tinha muita demanda. Na verdade aqueles dois cestos nem dava para começo. Eu vendia tudo. E os meus vizinhos começaram a se interessar. Ou, pelo menos, ficaram curiosos. Morando lá, eu não tinha nada para fazer, e frequentando a casa deles, ia levando a proposta. E o negócio foi crescendo. Um aderiu; outro aderiu; um terceiro aderiu... A gente comprou uma rural porque já não estava dando. Já tinha a minha produção, a do vizinho, a de um outro... E isso foi chamando a atenção, porque tudo o que a gente produzia, a gente vendia. E com isso, devagarzinho, a CONATURA foi se organizando tanto na área rural como na área urbana.

Eu gosto de dizer que foi, assim, uma organização bem orgânica. Não foi um pacote. A gente foi aprendendo. Todos nos idealistas, sem nenhuma capacitação gerencial. A gente estava fazendo aquilo tudo pelo ideal da agricultura orgânica e pelo ideal do cooperativismo. E deu certo! Porque se juntou, de um lado, agricultores que precisavam de uma opção de mercado e, do outro lado, um grupo de consumidores que já estava desperto para a questão dos alimentos contaminados. Então, a gente saiu de uma rural para uma combi. Aí, a combi já não estava dando, compramos outra combi. Desciam duas combis ${ }^{5}$. E depois, [como] já não estava dando, através de uma cotização entre os associados da cooperativa comprámos um caminhão. E quando também já não estava dando comprámos um segundo caminhão. Na sua época áurea, a CONATURA teve cerca de dois mil associados-consumidores. Produtores eram entre trinta a trinta e cinco famílias (Paulo Aguinaga, entrevista, 10/05/2013).

Paulo não localiza exatamente a época áurea da CONATURA. Mas ela se situa em torno do ano de 1990. Pelo seu relato, Paulo se torna uma pessoa importante na cooperativa, pois ele foi o elo de ligação entre o urbano e o rural. E é também na década de 1990, mais precisamente em 1994, que a CONATURA decide criar a primeira feira livre de agricultura orgânica do Rio de Janeiro - a feira da Glória. Essa feira que, nas palavras de Paulo, "foi o embrião do que é hoje o Circuito Carioca de Feira Orgânicas".

\footnotetext{
5 "Descer" aqui significa se deslocar à cidade do Rio de Janeiro.
} 
Isso [a criação da feira] foi em [na década de] 90. Fruto de uma experiência no Rio Grande do Sul. Uma cooperativa que a gente chamava irmã. Se chamava Colmeia. Nasceu um pouco depois da CONATURA, mas tinha uma história muito parecida e uma ideologia muito parecida. Então, volta e meia, nós estávamos sempre conversando. Numa dessas viagens que eu fiz lá ao Rio Grande do Sul, eu vi esse modelo de feira e disse: pô, vou levar isso para o Rio. E na época tinha um rapaz que trabalhava na Colmeia vindo para o Rio. Eu convidei ele para trabalhar na CONATURA e ficar responsável por organizar essa feira. Era o Nelson. E foi o Nelson quem fez a organização... quem criou o modelo da feira da Glória. Que, na verdade, se espelhou muito nessa feira que já existia, e existe até hoje, em Porto Alegre (idem).

A história da feira foi um elemento introduzido nesta primeira entrevista por uma pergunta minha bem específica. Na entrevista, Paulo estrutura o seu relato a partir do aumento "orgânico" do mercado de produtos orgânicos. Aumento esse que ele, conscientemente, traduz pela evolução da frota ao serviço da CONATURA. Por outro lado, a primeira impressão que fica da análise desta entrevista é que a experiência de vender nos supermercados, relativamente curta, foi um interlúdio entre 0 desaparecimento da CONATURA e o surgimento do Circuito Carioca de Feiras Orgânicas.

Isso foi na década de 1980 e no início da década de 90. [Tudo] funcionou muito bem. Não havia nenhuma loja... Mas é claro, como em todas as tendência de mercado, os supermercados logo se aperceberam que isso era uma tendência dos consumidores. E, no início da década de 1990, começaram a abrir espaço para os produtos orgânicos. As lojas [também] começaram a querer ter o produto orgânico principalmente as lojas de produto naturais. E esse foi um dos fatores que ajudaram à crise que a CONATURA viveu e que a obrigou a fechar. Ela não estava preparada para essa abertura do mercado. Como eu te disse, todo o mundo era idealista e amador, ninguém tinha capacidade técnica e gerencial para tocar um negócio daquele tamanho. A gente tinha um volume enorme e um custo enorme... E tudo isso foi gerando uma série de dificuldades financeiras até que chegou ao ponto em que a Assembleia de Associados decidiu então encerrar a atividade.

Nesse mesmo período, nessa fase interposto aí, os supermercados entram em força nesse mercado orgânico. Primeiro procurando produtores no Rio. Mas ninguém estava muito preparado para isso; para enfrentar ou para entrar nesse mercado extremamente profissional. Eles também trouxeram muitos produtos de São Paulo que já estavam um pouco mais avançados nessa linha. E é aí que entra a Horta Orgânica, uma associação [cuja] sede é no município de São José do Vale do Rio Preto. É um município vizinho a Petrópolis e bem perto do Brejal. E a turma que estava formando essa associação eram nossos conhecidos. Nos chamaram para ajudar... me chamaram para ajudar. E durante muito tempo, o grosso dos produtos comercializados pela Horta Orgânica saíram do núcleo de agricultores do Brejal. Nessa época, por conta da história da CONATURA, nós éramos o grupo mais organizado e mais acostumado a trabalhar com esse tipo de volumes.

A Horta fazia o papel de associação. Era fazer esse meio de campo administrativo entre o supermercado e o produtor. Então, a Horta recebia os pedidos do supermercado e repassava isso para os produtores. Os produtores entregavam lá; ela embalava, rotulava e fazia chegar nas lojas. Quando recebia o dinheiro, uma parte era para pagar essa estrutura da Horta, e a outra parte ela pagava aos produtores. Tinha uma planilha muito bem feira por um dos nossos diretores, Roberto Leite, que tinha muita facilidade para fazer esse tipo de planilhas. Então, uma coisa que funcionou muito na Horta Orgânica, que foi o que falhou na CONATURA, foi essa

Iluminuras, Porto Alegre, v. 14, n. 33, p. 87-99, jul./dez. 2013 
gestão empresarial. A gente tinha esses custos muito bem controlados, graças à experiência do Roberto Leite. [Mas] não era uma relação comercial no sentido de ser uma entidade privada: eu compro; eu lucro. Era uma entidade associativa com as contas abertas, as margens abertas, tudo era aberto.

Isso funcionou bem, deu bastante volume. Um fato bom dos supermercados é que ele deu volume à produção. Você não está falando mais de trinta, cinquenta ou cem caixinhas. Já está falando aí de quinhentas, seiscentas ou mil caixas. E isso de alguma forma foi bom; teve um estímulo da produção. Agora o problema é que os supermercados... A gente tem que elogiar eles, né? São muito profissionais. Mas eles não têm uma visão de parceria. Eles têm uma visão assim: negócio e só puxa para o lado deles. $\mathrm{E}$ as coisas foram ficando mais difíceis, com eles fazendo exigências e mais exigências. De bonificação, de troca, disso, daquilo... Até que chegou um ponto em que estava estrangulando. E justamente por causa dessa gestão empresarial muito correta e muito apurada... Não, vai dar; isso é suicídio. Ficar nos supermercados atendendo às exigências todas que eles estão fazendo é suicídio. E aí a gente parou e foi uma quebra geral, uma desilusão geral. Havia muita produção, havia muita...

Quer dizer, o mercado veio com a CONATURA, cresceu, cresceu... Depois com as lojas ele cresceu. E de repente fez assim. [Paulo, ia afastando as mãos subindo, desenhando um $V$ no ar e, de repente, junta as mãos como que desenhando uma linha horizontal encerrando, ou melhor, estrangulando esse V]. Nessa hora houve muito produtor que desistiu, muito produtor que parou... Foi difícil segurar o mercado nesse momento. Muitas empresas quebraram. E um pouco mais adiante chega o Circuito Carioca. Eles chegam num momento muito importante para absorver parte dessa produção que estava sem colocação no mercado... para reverter essa situação de um estímulo muito baixo ao produtor (ibidem).

Paulo Aguinaga, hoje, continua a produzir e tem uma pequena empresa por meio da qual comercializa a sua produção e de alguns vizinhos. Vende para lojas de produtos naturais e cooperativas de consumidores. Mas não participa nas feiras. Pode se dizer que ele trabalha com os canais de comercialização que ocuparam sempre uma posição secundária no mercado orgânico em face da CONATURA, dos supermercados, ou do Circuito Carioca. Mas que foram canais muito importantes nesses momentos de transição. A sua empresa, Bio-Hortas, nasceu em um desses momentos de transição. A Bio-Hortas, "foi criada nesse momento de crise da CONATURA". "Chegou um momento em que eu vi que tinha que fazer uma opção. E aí conversando, já no finalzinho da CONATURA, conversando para que o trabalho no Brejal não acabasse junto com a CONATURA, criamos essa microempresa e reestruturamos o trabalho lá" (Paulo Aguinaga, entrevista, 10/05/2013).

\section{Nota sobre capital simbólico}

Capital simbólico é, antes de mais nada, honra, estatuto, legitimidade, etc. Como falei acima, é se ter tornado a pessoa "certa". Um capital como os outros que pode ser convertido em outros: a marca de uma empresa pode ser vendida. Mas é também o efeito simbólico dos demais tipos de capital (Bourdieu, 2007: 296). Aqui, o que está em 
jogo é o fato de que os instrumentos de ação no mundo são também elementos de percepção do mundo. Assim, o proprietário de uma empresa pode vender o produto do trabalho de seus funcionários porque os instrumentos que organização o espaço social da empresa, das palavras aos contratos, legitimam essa ação. E, ao mesmo tempo, a economia do cálculo leva os agentes (exceto parcialmente ou exceto em situações de ambiguidade que condenam o agente a estar fora de tempo) a se guiar pelo capital simbólico em vez de computarem os outros capitais detidos por aqueles com quem interagem.

Ora, se capital simbólico pode ser, ao mesmo tempo, um capital $e$ o efeito simbólico dos demais capitais é porque o representante, o capital simbólico, é capaz de ganhar graus de autonomia do representado: os demais capitais. Bourdieu busca aqui uma generalização do fetiche da mercadoria segundo o qual o dinheiro não apenas ganha autonomia da mercadoria que representa, como subordina a produção de mercadorias e lhe impõe a sua lógica. Do mesmo modo, a reprodução dos capitais materiais do agentes não acontece senão por consequência da acumulação e reprodução de capital simbólico ${ }^{6}$. No entanto, esse ajustamento entre a reprodução do capital simbólico e os demais capitais nunca é perfeito. Ao ponto de existirem situação quixotescas, excepcionais, onde a reprodução do capital simbólico só pode se dar à conta da destruição dos demais capitais - um investimento, por isso mesmo, fadado ao fracasso.

Outrossim, Bourdieu define capital como a propriedade diferencial de recursos de poder. Isto é, o capital de um indivíduo não pode ser "medido" senão por referência a outros indivíduos. O que está aqui em jogo é a noção de campo, isto é, a construção sistemática e objetiva do sistema de diferenças entre os indivíduos. Isto remete para duas questões. Em primeiro lugar, o que delimita um objeto, unindo os indivíduos estudados; o que os separa, no seu conjunto, do resto da sociedade e em particular do sociólogo que os estuda? E, em segundo lugar, o que diferencia estes indivíduos entre si? Em suma, qual é a divisão social do trabalho existente, enquanto sistema de posições diferenciais entre indivíduos (que depende da quantidade e da qualidade dos

\footnotetext{
${ }^{6}$ Veja-se um exemplo oferecido por Pierre Bourdieu (2002). Na sociedade camponesa de Béarn anterior a 1914, o dote limitava as trocas económicas. Um jovem pobre não poderia oferecer um dote digno de uma menina rica. O casamento "de baixo para cima" era assim inviável. Mas essa limitação não se impunha por questões económicas, exceto em casos excecionais. Na generalidade dos casos, o efeito simbólico era por si mesmo dissuasor. Principalmente porque a diferença estatutária entre as famílias colidiria com a diferença estatutária entre marido e esposa e entre sogra e nora. E, deste modo, o casamento "de baixo para cima" colocaria o jovem noivo e sua mãe em uma situação potencialmente vexatória de terem que se subordinar à sua esposa e nora.
} 
capitais herdados por cada um); mas também enquanto organização prática e lógica da realidade social?

Se observa que Cristina e Paulo são detentores de um capital cultural elevado; ambos possuem uma graduação. Além disso têm suficiente capital econômico não apenas para investir na agricultura orgânica, mas igualmente para suportar os constantes reveses a que esse investimento está constantemente sujeito. De modo mais específico, todos possuem um capital cultural e econômico acumulado no meio urbano que é investido no meio rural.

Mas se, numa primeira análise, o capital econômico e o capital cultural os aproxima, eles estão separados pelas diferentes espécies de capital social ${ }^{7}$ que possuem. A rede de relações de Cristina, por força dos seus investimentos passados, é capaz de mobilizar um capital burocrático, esse capital ligado à força do Estado. E não apenas isso. O capital social de Cristina e, portanto, seu capital simbólico, depende disso. Ela está disposta a empenhar o capital econômico dos agricultores que pode mobilizar em sua rede para acumular aquele capital social específico que lhe dá acesso ao capital burocrático. Por isso esteve disposta a investir na arriscada e fracassada feira dos Arcos da Lapa (criticada em algumas entrevistas que já realizei) que, apesar de tudo, não deixou de ser um passo para a criação do Circuito Carioca de Feiras Orgânicas. Por oposição, a rede de relações de Paulo é quase de natureza puramente econômica: com supermercados, com cooperativas de consumo, com lojas de produtos naturais, etc.

Por outro lado, essa diferença aparece como a oposição entre presente e passado. Paulo está para a época dos supermercados como Cristina está para a época atual, do circuito. Isto coloca o problema da co-presença entre passado e presente na mesma totalidade social. É impossível tratar desse assunto aqui. Basta somente assinalar que, na teoria social, esse problema tem recebido tratamentos tão diversos como aquele proposto por Halbwachs (2006) e aquele proposto por Ricouer. Num cenário ideal, a pesquisa futura permitirá até confrontar as duas propostas e deixar a realidade empírica decidir qual se adequa melhor.

Se ficássemos por aqui capital simbólico seria apenas o efeito simbólico dos demais capitais. Num segundo momento, do qual não é ainda possível sequer uma primeira aproximação, é necessário compreender como a ação estratégica dos indivíduos. Isto é, como eles, com a liberdade dada pela ambiguidade na relação entre o

\footnotetext{
${ }^{7}$ Entendo aqui capital social no sentido de Bourdieu (1998): enquanto acesso diferencial de um agente a um conjunto de recursos devido à pertença a determinada rede de relações ou grupo social.
} 
capital simbólico e os demais capitais, procuram transformar essa distribuição de capitais e essa divisão social do trabalho.

\section{Referência}

BERTAUX, D. L'Approche biographique. Sa validité méthodologique, ses potentialités. Cahiers Internationaux de Sociologie [S.I.], v. LXIX, n. 2, p. 198 - 225, Jul-Dez 1980.

BOURDIEU, P. O capital social - notas provisórias. In: NOGUEIRA, M. A.; CATANI, A. (Ed.). Pierre Bourdieu: escritos de educação. Petrópolis: Editora Vozes, 1998. p. 65-79.

Le bal des célibataires. Paris: Édition du Seuil, 2002.

. Meditações pascalianas. Rio de Janeiro: Bertrand Brasil, 2007.

FONSECA, F. $O$ estudo do mercado de alimentos orgânicos (frutas, legumes e verduras) in natura no Estado do Rio de Janeiro: o caso da ABIO. Rio de Janeiro: CPDA/UFRRJ (dissertação de mestrado), 1999.

HALBWACH, M. A memória coletiva. São Paulo: Centauro, 2006.

RICOUER, P. Narrative time. Critical inquiry [S.I.], v. 7, n. 1, p. 169-190, 1980.

Recebido: $15 / 08 / 2013$

Aprovado: 21/08/2013 